\title{
Geliat Komik Indonesia
}

\author{
Hanny Hafiar dan Oji Kurniadi
}

\begin{abstract}
The expectation to send the victory of Indonesian comics as well as in 1960 is getting wider. The rising of Indonesian youth comic maker through the big or Indy publishing house is one of the indications. But the expectation would be blown by a lot of problems. The problems are the quality of drawing and story line from young comic maker that still adopts Japanese style, the existence of porn illegal comics decreases attention of reader to read local comics, suboptimal controlling of government to illegal publishing and the pride less of our society to their own products. Teamwork from a lot of element with each portion is a must to handle the problems, so we can hope that foreign comic which is some time inappropriate with our culture not dominate Indonesian comics industry anymore.
\end{abstract}

Kata kunci: komik Indonesia, manga, penerbit indie

\section{Fenomena Komik di Indonesia}

Ada gula ada semut. Pepatah tersebut mencerminkan keadaan bisnis komik di Indonesia. Tingginya animo pembaca komik di Indonesia menyebabkan menjamurnya perusahaan penerbit dan pendistribusi komik di Indonesia, baik legal maupun ilegal. Hal ini dilakukan untuk memenuhi permintaan pasar yang cukup tinggi terhadap komik-komik yang dianggap menarik untuk dibaca.

Komik adalah suatu bentuk seni yang menggunakan gambar-gambar tidak bergerak, yang disusun sedemikian rupa, sehingga membentuk jalinan cerita serta dilengkapi dengan teks. Komik dapat diterbitkan dalam berbagai bentuk seperti strip dalam koran atau majalah, hingga dibuat seperti buku.

Komik yang beredar di Indonesia didominasi oleh komik yang dibuat oleh pembuat komik atau mengaka asal Jepang, yang diterjemahkan dan dikemas ulang oleh penerbit di Indonesia seperti PT. Elexmedia Komputindo, M\&C, Level Comics, Dragon Comics, Sakura, dan Tiga Serangkai dll.

Karena isi ceritanya menarik, gambarnya bagus, dan hasil terjemahannya sesuai dengan konteks, maka komik Jepang yang biasa disebut dengan Manga dengan cepat dapat memeroleh popularitas di kalangan pecinta komik Indonesia, sehingga nama-nama seperti Adachi Mitsuru, Yukari Kawachi, Eriko Onno, dan Naoki Urosawa, segera melekat di benak pembaca komik sebagai mangaka yang memiliki hasil karya yang ditunggutunggu.

\section{Pengaruh Komik terhadap Berbagai Bidang}

Popularitas komik telah memengaruhi dunia seni peran, karena dewasa ini muncul fenomena pembuatan sinetron yang ide ceritanya diadaptasi 
dari jalan cerita sebuah komik yang biasa disebut dorama. Beberapa dorama ini bahkan sempat booming di pasaran. Hal ini merujuk pada serial "Meteor Garden" yang diproduksi Taiwan, yang mampu meraup jutaan dolar dan disiarkan di berbagai negara, baik di Asia ataupun di Eropa.

"Meteor Garden" merupakan serial TV yang memopulerkan nama Jerry Yan, Vic Zhou, Ken Zhu, serta bintang muda Taiwan lainnya, yang sampai saat ini masih identik dengan tokoh Tao Ming Tse, Hua Ce Lei, dan Xie Men sebagai karakter anggota F4 yang ada dalam komik Hana Yori Dango besutan Yoko Kamio seorang mangaka senior asal jepang.

Sesungguhnya, isi cerita komik yang diadaptasi menjadi tayangan televisi sudah lama terjadi, namun kebanyakan bentuk tayangannya pun berbentuk animasi yang diistilahkan menjadi Anime. Contohnya adalah serial Doraemon, Detective Conan, Crayon Shinchan, Kobo Chan, Chibi Maruko, Dragon Ball, dan Kapten Tsubasa.

Popularitas komik tidak hanya menyemarakkan dunia pertelevisian, namun juga merambah ke dunia fashion dengan kemunculan Harajuku Style dan Lolita style, yang menginspirasi para penikmat mode untuk mencoba bereksperimen dengan gaya berpakaian yang ditampilkan oleh karakter tokoh dalam komik berjudul Gals karya Mihona Fuji.

Selain itu, komik juga menyemangati para pembuat program permainan interaktif, baik yang berbentuk game computer maupun game console. Komik Jepang berjudul Sengoku karya Hideki Miyashita dan Ragnarok karya Lee Myung Jin asal Korea merupakan komik yang telah diadaptasi menjadi sebuah game online yang banyak diminati para gamer di Indonesia.

Masih banyak contoh lain dari pengaruh booming komik dalam berbagai bidang, seperti munculnya situs-situs yang menjadi wadah para penggemar komik, merchandise dengan berbagai gambar karakter komik ataupun m-komik (mobile comic) yang menggunakan fasilitas seluler. Hal ini, tentunya, merangsang tumbuhnya bisnis baru yang melibatkan komik secara langsung ataupun tidak langsung sebagai salah satu industri yang layak mengundang perhatian investor.
Namun, fenomena yang paling menarik untuk diamati adalah munculnya manga school, atau lembaga pendidikan yang menyediakan pengajaran cara membuat komik. Hal ini dianggap menarik mengingat dengan adanya sekolah atau lembaga kursus pembuat komik, maka diharapkan akan muncul minat anak bangsa untuk meramaikan kancah perkomikan di Indonesia dengan karyanya sendiri yang orisinal dan kontekstual dengan keadaan serta budaya bangsanya sendiri. Jika hal ini terjadi, maka secercah harapan akan munculnya geliat komik Indonesia ke permukaan dan tidak lagi ditenggelamkan oleh komik impor bukanlah merupakan sebuah utopia.

\section{Perkembangan Komik di Indonesia}

Sesungguhnya, komik Indonesia sempat menjadi tuan rumah di negaranya sendiri berkat karya-karya R.A. Kosasih, Adisoma, Jan Mintaraga, maupun Hans Jaladara, yang mengangkat kisah pewayangan, pahlawan rekaan yang bernuansa lokal, maupun cerita remaja ala Indonesia. Namun, seiring perkembangan zaman, sejak tahun 90-an komik yang diminati masyarakat bergeser menjadi Kungfu Boy, Candy-Candy ataupun City Hunter karya komikus Jepang. Pergeseran ini menyebabkan komik Indonesia tidak lagi banyak diminati pembacanya. Hal ini dapat diamati melalui minimnya ketersedian komik lokal dibandingkan dengan komik impor di berbagai toko buku.

Seyogianya, dengan keberadaan manga school yang mulai bertebaran di kota-kota besar, diharapkan dapat menjadi konduktor bagi anak negeri yang berbakat dalam bidang grafis untuk menghasilkan karya sendiri yang patut ditunggutunggu oleh para penggemar komik di Indonesia, sehingga komik Indonesia dapat bangkit kembali menjadi raja di negaranya sendiri.

Keberadaan manga school di Indonesia, setidaknya telah membawa angin segar bagi para peminat grafis yang ingin membuat komik, karena para sensei di manga school memberikan pemahaman dan pengasahan tentang cara membuat komik, baik dari penyusunan alur cerita hingga pembuatan gambar. Para sensei yang 
Terakreditasi Dirjen Dikti SK No. 56/DIKTI/Kep/2005

sebagian berasal dari Jepang juga memperkenalkan alat-alat khusus seperti toning, striping, mata pena dll, untuk membuat komik, agar tiap frame dari komik memiliki nilai artistik yang lebih baik.

Selain itu, perkembangan menarik lainnya adalah munculnya wadah-wadah pecinta komik yang aktif melakukan berbagai kegiatan, seperti pameran komik, seminar tentang komik, jumpa komikus, bahkan sharing info mengenai cara-cara penerbitan komik, baik menggunakan jalur penerbit besar maupun penerbit indie. Melalui berbagai kegiatan inilah yang akhirnya membangkitkan minat komikus muda Indonesia untuk mencoba membuat dan mempulikasikan karyanya sendiri.

Indikasi kebangkitan komikus tanah air ditandai dengan kemunculan komikus muda yang mulai mempublikasikan hasil karyanya seperti Anzu, Shinju Arisa, T-Wolv, Hiei-D, Calista, Lily, Blue Sea, Kartika, Mega Ashtari ataupun Cynara. Meskipun jumlah hasil karyanya masih terbatas, namun Tankôbon (komik berupa buku) mereka sudah diterbitkan oleh penerbit sebesar PT. Elexmedia Komputindo, anak perusahaan Kelompok Kompas Gramedia, yang merupakan perusahaan penerbit dengan jaringan usaha yang tersebar di seluruh Indonesia, ataupun oleh penerbit indie yang sudah memiliki nama.

Munculnya komikus muda yang ingin memublikasikan hasil karyanya, memancing insting bisnis para pengusaha yang memiliki kepedulian pada dunia komik untuk membuka usaha di bidang penerbitan, baik yang langsung berskala nasional ataupun yang masih berlabel indie. Dengan maraknya usaha penerbitan komik, diharapkan mampu mendongkrak kuantitas dan kualitas komik lokal yang beredar di pasaran, sehingga hasil karya komikus Indonesia dapat disejajarkan dengan manga dari Jepang, manhua dari Cina ataupun manhwa dari Korea.

Perkembangan ini juga diharapkan mampu memperluas cakrawala pembaca komik Indonesia tentang budaya bangsa sendiri, sehingga para pembaca usia muda di Indonesia tidak lagi dijejali oleh budaya khas bangsa lain seperti Tanabata, Kabuki, upacara minum teh, white day, ataupun Yukata. Namun juga memahami konsep dan makna midodareni, kenduri, khitanan, ataupun kemben.

\section{Kendala bagi Komik Indonesia}

Kebangkitan komik Indonesia di tanah air ini tidak mudah diwujudkan begitu saja mengingat melibatkan banyak faktor bersifat kompleks yang melingkupinya. Sebut saja, misalnya kreativitas komikus muda Indonesia yang masih berkiblat pada gaya berkomik mangaka Jepang.

Hal ini terlihat dengan adanya penyebutan identitas diri berbau Jepang, seperti Anzu dan Shinju Arisa, sebagai nama samaran dari sang komikus Indonesia. Selain itu, setting dan alur cerita yang diangkat komikus muda Indonesia pun masih bergaya Jepang. Penggunaan seragam bermodel sailor layaknya seragam sekolah di Jepang ataupun mengangkat kisah cinta di antara teman sejak kecil yang merupakan ciri khas alur cerita komik Jepang.

Artinya, komikus muda Indonesia belum memiliki keteguhan hati untuk menampilkan seragam putih abu-abu dan kisah cinta ala Siti Nurbaya yang merupakan realita dalam budaya Indonesia. Padahal, sesungguhnya jika komikus muda ingin meraih popularitas di hati pembaca Indonesia maka setting dan alur cerita dalam komik, sebaiknya disesuaikan dengan konteks dan budaya bangsa Indonesia. Hal ini merujuk pada pernyataan: dalam bergaul dengan orang sebangsa, semakin mematuhi aturan masyarakat maka akan semakin populer (Lewis, 2004 : 22).

Selanjutnya, kualitas gambar dalam komik dapat ditentukan oleh alat dan bahan yang digunakan dalam pembuatan komik. Dengan demikian, ketidaklengkapan alat dan bahan pembutan komik yang tersedia di pasaran mampu memengaruhi kualitas hasil karya komikus muda Indonesia. Untuk itu, diharapkan para wirausahawan yang jeli mampu melihat peluang bisnis ini untuk memenuhi permintaan pasar agar alat dan bahan pembuatan komik di Indonesia, baik dengan cara mengimpor maupun dengan cara mencari bentuk dan bahan alternatife tanpa mengurangi nilai fungsi.

Kelengkapan dan ketersediaan alat serta bahan pembuatan komik ini akan memudahkan para 
komikus untuk meningkatkan kualitas gambar mereka. Jika kualitas gambar sudah dapat ditingkatkan, bukan mustahil peluang komik Indonesia untuk laku di pasaran menjadi lebih terbuka, karena hasil karya yang berkualitas termasuk ke dalam elemen product dalam konsep bauran pemasaran selain price, place dan promotion (Kotler, 1987 :63).

Permasalahan berikutnya adalah ketergantungan komikus pada penerbit besar. Tingginya ekspektasi komikus agar hasil karyanya dapat dipublikasikan oleh penerbit besar, membuat komikus muda Indonesia tidak memiliki kuasa untuk berpartisipasi dalam penentuan harga hasil karyanya. Akibatnya, harga komik para debutan berbandrol harga yang sama dengan komik impor yang dibuat mangaka ternama dan meraih best seller di negeri asalnya. Kenyataan ini tentu melemahkan kesempatan para debutan untuk meraih perhatian pembaca karena tidak bias bersaing dalam hal harga.

Boleh jadi, pertimbangan penerbit besar untuk menetapkan harga yang sama bagi seluruh jenis komik terlepas dari siapa dan dari mana asal komikusnya mengacu pada pemikiran sistem ekonomi pasar terbuka yang biasa digunakan oleh perusahaan yang berkaitan dengan media. Hal ini merujuk pada pernyataan Murdock dan Golding (1977) bahwa:

The ownership of comodity by private capital is subject to a general process of concentration via conglomeration, this produce multi media corporations which are part of a wider process of capital conglomeration (Barker, 2000 : 278-279).

Pemodal swasta yang memiliki sebuah komoditas cenderung tunduk pada sebuah proses umum yang terkonsentrasi melalui konglomerasi, hal ini mengakibatkan keberadaan berbagai perusahaan media hanyalah sebagai bagian dari proses kegiatan yang lebih besar dari para pemilik modal.

Terdapat alternatiflain untuk tetap memajukan komik Indonesia dalam menyiasati hadangan kapitalis, yaitu melalui pemanfaatan penerbit indie. Pada umumnya, penerbit indie dapat dikatakan sebagai lembaga usaha yang bergerak di bidang penerbitan atau percetakan yang memiliki otoritas sendiri dan dapat melakukan kegiatan mandiri tanpa harus mematuhi grand design atau pakem yang ditetapkan oleh pemilik modal yang menaunginya. Hal ini mengacu pada pendefinisian indie sebagai not depending upon otority of another, not in position of subordinate, not subject to extern control of rule: self governing, free (Taylor dan Wilis, 1999: 132).

Keleluasaan yang dimiliki oleh penerbit indie untuk sepenuhnya memegang kontrol atas kegiatan usahanya disebabkan adanya sifat yang dimiliki penerbit indie sebagai salah satu perusahaan yang bergerak di bidang media, yaitu absolute independent, would mean that media organization had control of production, distribution and exhibition (Taylor dan Wilis, 1999 : 133).

Batu sandungan lain yang harus dihadapi komik Indonesia sebelum mencuat ke permukaan adalah bocornya pengawasan pemerintah terhadap komik-komik ilegal. Adapun yang dimaksud dengan komik ilegal adalah komik produksi negara lain yang diterjemahkan secara bebas oleh penerbit yang anonim serta beredar di indonesia tanpa diketahui oleh komikus ataupun penerbit pemegang lisensinya.

Maraknya komik ilegal yang kebanyakan diproduksi di Surabaya ini dapat memengaruhi iklim kompetisi dalam dunia bisnis perkomikan. Walau bagaimana pun, komik ilegal tidak membutuhkan biaya untuk membayar lisensi pada penerbit asli, royalti pada komikus, pajak pada pemerintah, penerjemah profesional, badan sensor, dan lain sebagainya, sehingga ongkos produksi dapat ditekan serendah mungkin. Untuk itu, dalam hal ini dibutuhkan peranan pemerintah untuk memperketat pengawasan dan mempersempit ruang gerak komik ilegal dengan cara melakukan penelusuran melalui kios penyewaan komik yang biasanya menjadi pembeli komik ilegal ini.

Dengan demikian, dukungan pemerintah untuk mengatur sistem usaha masyarakat sangat diperlukan, agar persaingan sehat yang seharusnya dihadapi komik lokal yang legal, dapat diwujudkan. Hal ini merujuk pada salah satu 
Terakreditasi Dirjen Dikti SK No. 56/DIKTI/Kep/2005

peranan pemerintah dalam kegiatan ekonomi, yaitu membuat peraturan agar kegiatan ekonomi masyarakat dapat dijalankan secara wajar dan tidak merugikan khalayak ramai (Sukirno, 2003, 47).

Peranan pemerintah dalam membuat peraturan kegiatan ekonomi masyarakat meliputi peranan pengawasan dan penegakan peraturan tersebut. Dengan demikian, apabila pemerintah telah mampu melaksanakan tugasnya dalam pengawasan kegiatan usaha masyarakat, termasuk menertibkan komik illegal di Indonesia, maka kekhawatiran tentang adanya khalayak yang dirugikan, misalnya pelaku bisnis penerbit indie yang berijin resmi, dapat dieliminasi.

Selain membawa dampak buruk dari segi bisnis, keberadaan komik ilegal di Indonesia, ternyata secara tidak langsung memengaruhi minat pembaca pada komik lokal. Hal ini disebabkan komik ilegal yang beredar banyak yang bermuatan unsur pornografi. Perputaran penyewaan komik jenis ini di beberapa kios penyewaan komik, termasuk tinggi dan mengalahkan perputaran pnyewaan komik lokal. Fakta ini menunjukkan bahwa komik ilegal bermuatan porno lebih diminati oleh penyewa komik yang mayoritas berstatus pelajar, daripada komik lokal.

Komik yang dapat dikategorikan ke dalam hentai atau ecchi ini biasanya diproduksi oleh penerbit indie di Jepang yang diproduksi menggunakan teknik xerografi (fotocopy), print/ publish on demand (dicetak dan diterbitkan atas permintaan), serta disebarkan melalui website. Artinya, memang tidak ada campur tangan lembaga sensor dalam penerbitannya. Lagi pula, terdapat perbedaan batasan pornografi yang berlaku di Jepang dengan batasan pornografi di Indonesia. Tidak mengherankan jika media publikasi yang pasti akan dianggap bermuatan hal tabu di Indonesia, ternyata beredar secara resmi dan bebas di Jepang.

Keberadaan komik asing ilegal berlabel " $21+$ " atau komik yang diperuntukan untuk orang dewasa ini, dikhawatirkan dengan mudah dibaca oleh pembaca usia sekolah di Indonesia, karena hanya dengan ongkos sewa yang reatif murah, komik porno dapat dipinjam di berbagai kios penyewaan komik. Padahal, sudah banyak hasil penelitian dan berita di media massa yang menginformasikan bahwa pornomedia dalam berbagai bentuk baik pornografi, pornoteks, pornosuara, maupun pornoaksi, dapat menjadi pemicu berbagai tindakan kriminal seksual di kalangan remaja. Tidak mengherankan jika para sosiolog menempatkan pornomedia sebagai bentuk patologi sosial (Bungin, 2006:338).

\section{Penutup}

Jika meninjau faktor kendala, maka terlihat dengan gamblang bahwa dibutuhkan upaya keras dan kerjasama yang solid antarsemua pihak yang terkait agar komik Indonesia bisa kembali berjaya di blantika media tanah air. Berbagai aspek yang dapat memberi kontribusi pada pencapaian tujuan ini, antara lain, peningkatan pengawasan pemerintah melalui penegakan aturan bisnis yang menjamin ketertiban kegiatan usaha masyarakat, peningkatan kepedulian penerbit swasta melalui pertimbangan yang populis pada aspek penetapan harga komik lokal, peningkatan upaya penerbit indie untuk tetap idealis dan berpihak pada kepentingan komikus yang termajinalisasi, peningkatan kerja keras komikus Indonesia untuk dapat menghasilkan karya yang mengundang minat pembaca, peningkatan partisipasi komunitas pecinta komik dalam berbagi kegiatan publisitas dan bisnis demi kepentingn komik lokal, serta kesadaran masyarakat untuk lebih mencintai dan menghargai hasil karya bangsa sendiri.

Jika hal-hal tersebut secara bertahap dapat dilakukan, maka secercah harapan indah bahwa komik Indonesia akan kembali berjaya dan dapat disandingkan dengan komik luar, bukanlah merupakan impian kosong. Karena pada kenyataannya, industri komik di Jepang bukan lagi sekadar industri yang berbasis pada hobi melainkan industri yang sudah dapat memberikan keuntungan jutaan Yen pada Negeri Sakura. Selain itu, pekerjaan komikus bukan lagi merupakan pekerjaan sampingan untuk mengisi waktu luang melainkan sudah menjadi profesi yang diakui dan dihormati.

Berdasarkan fakta tersebut maka sudah 
sepatutnya semua pihak bersungguh-sungguh menjalankan fungsinya dalam menggerakan mesin industri komik di Indonesia agar kelak anak cucu bangsa Indonesia dapat berbangga saat menyaksikan tayangan anime produksi Indonesia di stasiun televisi berskala internasional di luar negeri.

\section{Daftar Pustaka}

Barker, Chris. 2000. Cultural Studies: Theory and Practice. London: Thousand Oaks and New Delhi: Sage Publications.
Bungin, Burhan. 2006. Sosiologi Komunikasi: Teori, Paradigma dan Diskursus Teknologi Komunikasi di Masyarakat. Jakarta: Kencana Prenada.

Kotler, philip. 1987. Dasar-dasar Pemasaran: Edisi Ketiga. Jakarta: Intermedia.

Lewis, Richard D. 2004. Komunikasi Bisnis Lintas Budaya. Bandung: PT Remaja Rosdakarya.

Sukirno, Sadono. 2003. Pengantar Teori Mikroekonomi: Edisi Ketiga. Jakarta: RajaGrafindo Persada.

Taylor, Lisa and Andrew Wilis. 1999. Media Studies: Texts, Institutions and Audiences. Oxford: Blackwell Publishing. 